\title{
Analisis Jarak Gading dan Kekuatan Batas Struktur Kapal Ferry Ro-Ro
}

\author{
Amalia Ika Wulandari ${ }^{1 *}$, Ganding Sitepu ${ }^{1}$, Muhammad Zubair Muis Alie ${ }^{1}$ \\ ${ }^{1}$ Departemen Teknik Perkapalan, Fakultas Teknik, Universitas Hasanuddin \\ Jl. Poros Malino Km. 6, Bontomarannu, Kabupaten Gowa, Sulawesi Selatan, 92171 \\ *Email : amaliaikaw@yahoo.com
}

DOI: 10.25042/jpe.052018.02

\begin{abstract}
Abstrak
Perkembangan peraturan konstruksi tidak lagi mengatur jarak gading. Sehingga para perancang kapal merencanakan jarak gading yang optimal dengan batasan resiko tekuk pada pelat menurut peraturan klasifikasi, momen batas struktur kapal harus sama dengan atau lebih besar dari 1,2 kali momen lentur vertikal (sagging dan hogging). Momen lentur vertikal dihitung dengan menggunakan formulasi yang telah diberikan oleh BKI. Penelitian ini bertujuan untuk mengetahui kekuatan batas pada struktur kapal ferry Ro-Ro yang membandingkan hasil dari dua metode yaitu Metode Smith dan NLFEA. Ro-Ro adalah kapal yang menangani muatannya dengan cara rolling it on and off di atas single or series ramps. Ramps yang dapat bekerja baik saat di kapal dan dermaga. Pada penelitian ini menunjukkan perbandingan nilai hasil dari metode NLFEA lebih besar daripada metode Smith. Hal ini dikarenakan metode NLFEA dapat menghitung redistribusi beban dan interaksi antara kegagalan lokal dan global secara kompleks sehingga keakuratan hasil perhitungan metode NLFEA lebih baik daripada metode Smith. Semakin jauh jarak gading maka semakin kecil beban batas agar pelat mengalami tekuk.
\end{abstract}

\begin{abstract}
Analysis of Frame Space and Ultimate Strength of Ro-Ro Ferry Structure. The development of construction's regulation is no longer determining the distance of the frame. Hence, the designers make the optimal frame distance plan with the ultimate risk of bending on the plate. According to the classification rules, the structure's ultimate moment must be equal to or greater than 1.2 times vertical bending moment (sagging and hogging). This study aims to determine the ultimate strength on the structure of a Ro-Ro ferry which comparing two methods between the Smith and NLFEA Methods. Ro-Ro is a ship that handles its cargo by rolling it on and off over a single or ramp series. Ramps that can work well on board and dock. The use of ANSYS application that applied NLFEA method in this study shows the comparison of result value of NLFEA method is greater than Smith method. This is because the NLFEA method can calculate load redistribution and the interaction between local and global failures in a complex way so that the accuracy of the NLFEA method is better than the Smith method. The further the ivory distance the smaller the ultimate load for the plate to buckling.
\end{abstract}

Kata Kunci: Jarak gading, kekuatan batas, kapal ro-ro, penampang melintang, tekuk

\section{Pendahuluan}

Masalah utama dalam konstruksi kapal ialah membuat suatu konstruksi yang kokoh dan kuat dengan berat konstruksi yang seringan mungkin. Konstruksi yang kuat dan ringan untuk mendapatkan daya muat yang besar sehingga menguntungkan. Dengan berkembangnya teknologi di bidang konstruksi kapal, pemilihan desain dan material merupakan sesuatu hal yang sangat dipertimbangkan oleh perusahaan galangan kapal dalam perancangan dan pembuatan kapal baru. Konstruksi kuat dan kokoh merupakan suatu konstruksi yang tidak mudah patah dan tidak berubah bentuk saat menerima beban.

Kekuatan kapal merupakan faktor yang harus diperhitungkan dalam pembangunan suatu kapal. Faktor yang mempengaruhi kekuatan kapal adalah jarak gading, panjang tak ditumpu, tebal pelat dan lain-lain. Perkembangan peraturan konstruksi tidak lagi mengatur jarak gading. Sehingga para perancang kapal merencanakan jarak gading yang optimal dengan batasan resiko tekuk pada pelat Menurut peraturan klasifikasi, momen batas struktur kapal harus sama dengan atau lebih besar dari 1,2 kali momen lentur vertikal (sagging dan 
hogging). Momen lentur vertikal dapat dihitung dengan menggunakan formulasi yang telah diberikan oleh BKI sedangkan momen batas dapat diperoleh dengan menggunakan NLFEA (Nonlinear Finite Element Analysis). Dengan memperhatikan perubahan jarak gading maka dapat diketahui momen batas struktur agar pelat geladak kapal tidak mengalami tekuk (buckling). Dalam hal pelat mendapatkan tekanan dari sisisisinya, maka bila jarak gading dekat kegagalan akan terjadi karena material mengalami luluh (yielding), jika jarak gading jauh (jarang) maka kegagalan akan terjadi karena pelat mengalami tekuk [1]. Penggunaan aplikasi NLFEA memungkinkan untuk mengetahui informasi penting terkait analisa struktur yang kompleks terutama dalam industri maritim [2]. NLFEA dapat menyelesaikan masalah struktur meliputi analisa tegangan, buckling dan analisa getaran. Penyelesaian dari persoalan-persoalan struktur yang kompleks dapat diselesaikan dengan formulasi dari metode elemen hingga. Metode ini akan melakukan pendekatan terhadap nilai-nilai yang tidak diketahui pada setiap titik secara diskrit [3].

Kapal Ro-Ro dengan penciriannya adalah rasio H/B (Tinggi dan lebar kapal) relatif kecil agar kendaraan mudah roll on dan roll off, di lain sisi H/B (Perbandingan Tinggi dan Lebar) yang kecil menyebabkan momen inersia penampang midship relatif kecil sehingga tegangan pada pelat geladak cenderung besar pada kondisi sagging. Adapun masalah yang akan dianalisis pada penelitian ini adalah bagaimana kekuatan batas kapal ferry Ro-Ro yang akan dibandingkan antara dua metode yaitu NLFEA dan Smith.

Adapun tujuan penelitian ini adalah menganalisis kekuatan batas struktur kapal pada kondisi sagging dan hogging dengan metode Smith dan NLFEA. Pengaruh jarak gading terhadap tekuk pada pelat.

\section{Pembahasan}

Kapal Ro-Ro adalah kapal yang bisa memuat kendaraan yang berjalan masuk ke dalam kapal dengan penggeraknya sendiri dan bisa keluar dengan sendiri juga, sehingga disebut sebagai kapal roll on-roll off atau disingkat Ro-Ro. Oleh karena itu, kapal ini dilengkapi dengan pintu rampa yang dihubungkan dengan moveble bridge atau dermaga apung ke dermaga. Kapal Ro-Ro selain digunakan untuk angkutan truk juga digunakan untuk mengangkut mobil penumpang, sepeda motor serta penumpang jalan kaki.

Ro-Ro adalah kapal yang menangani muatannya dengan cara rolling it on and off di atas single or series ramps. Ramps yang dapat bekerja baik saat di kapal dan dermaga. Untuk menyempurnakan bongkar dan muat dari geladak yang berbeda pada geladak dibutuhkan internal ramps. Hal ini juga membutuhkan spasi dari ruang muat [4]. Keunikan dari kapal Ro-Ro antara lain:

1. Memiliki akses ramp pada bow, stern atau sisinya tetapi tidak harus semua ramp terdapat pada Ro-Ro;

2. Memiliki geladak kendaraan dengan lajur yang yang panjang;

3. Memiliki banyak ventilator pada atas deck sebagai tempat pembuangan asap kendaraan saat bongkar dan muat.

Kekuatan batas adalah batas kekuatan struktur untuk mengalami pembebanan maksimum sebelum mengalami collapse total [5]. Perhitungan kekuatan batas kapal ferry Ro-Ro berdasarkan keakuratan dan kompleksitas hingga saat ini terdiri dari 5 metode yaitu: teori balok, metode Presumed Stress Distrbution, metode Smith dan Idealized Structural Unit Method (ISUM), Intelligent Supersize Finite Element Method (ISFEM), dan NLFEA. Momen lentur batas vertikal dalam analisa kekuatan struktur kapal terdiri dari beban pada air tenang $\left(\mathrm{M}_{\mathrm{sw}}\right)$ untuk skenario pembebanan statis dan penjumlahan beban pada air tenang $\left(\mathrm{M}_{\mathrm{sw}}\right)$ dan beban akibat gelombang $\left(\mathrm{M}_{\mathrm{W}}\right)$ untuk skenario pembebanan statis dan dinamis [5]. Menjumlahkan momen lentur batas vertikal pada air tenang dan momen lentur batas vertikal akibat gelombang untuk mendapatkan nilai ekstrim dari momen lentur batas vertikal. Beban dinamis longitudinal diakibatkan oleh gelombang. Ketika kapal berada pada puncak gelombang, kapal mengalami momen lentur dan gaya geser yang disebut hogging. Ketika kapal berada di lembah 
gelombang, kapal mengalami momen lentur dan gaya geser yang disebut sagging. Kombinasi beban statis dan dinamis $\left(\mathrm{M}_{\mathrm{t}}\right)$ untuk menganalisa kekuatan kapal terhadap momen lentur batas vertikal dihitung dengan penjumlahan momen lentur batas vertikal pada air tenang dan momen lentur batas vertikal akibat gelombang. Momen batas kapal ferry $\left(\mathrm{M}_{\mathrm{u}}\right)$ harus dihitung dengan metode NLFEA atau metode buckling dan harus memenuhi kriteria seperti persamaan 1 [5].

$$
M_{t}=M_{S W}+1,2 M_{W}
$$

dimana $\mathrm{M}_{\mathrm{t}}$ adalah momen lentur batas total vertikal dan $\gamma_{R}$ adalah faktor keamanan untuk kekuatan batas lentur vertikal (1,2 untuk kondisi sagging dan 1,21 untuk kondisi hogging). $\mathrm{C}_{\mathrm{V}}$ adalah stress factor [6].

Tekuk adalah suatu ragam kegagalan yang diakibatkan oleh ketidakstabilan suatu elemen struktur yang dipengaruhi oleh aksi beban. Kegagalan yang diakibatkan oleh ketidakstabilan dapat terjadi pada berbagai material. Pada saat tekuk terjadi, taraf gaya internal dapat sangat rendah. Fenomena tekuk berkaitan dengan kekakuan elemen struktur. Suatu elemen yang mempunyai kekakuan kecil lebih mudah mengalami tekuk dibandingkan dengan yang mempunyai kekakuan besar. Semakin panjang suatu elemen struktur maka semakin kecil kekakuannya [1]. Bentuk/model tekuk dari deformasi pelat berpenegar secara transversal dibawah pengaruh beban orthogonal bidang searah dengan penegar adalah:

a. Tekuk pada panel pelat antara penegar;

b. Tekuk dari penegar;

c. Tekuk lentur dari kombinasi pelat berpenegar (tekuk global pada bidang berpenegar).

Berbagai model tekuk deformasi dari penegar yang diberi beban pada bidang pada arah yang sama dari penegar adalah:

a. Tekuk lentur dari penegar;

b. Tekuk puntir dari penegar;

c. Tekuk lateral dari penegar;

d. Tekuk global pada penegar dengan pelat ikutan;

e. Tekuk lokal pada web plate dari penegar;

f. Tekuk lokal pada face plate dari penegar.
Model deformasi dari tekuk lentur dari penegar dapat dilihat pada Gambar 1 [6].

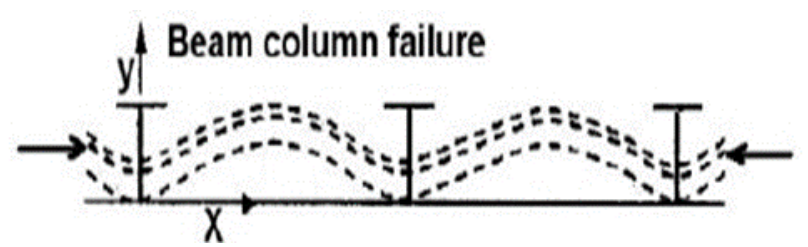

Gambar 1. Bentuk deformasi dari pelat berpenegar longitudinal dalam pengaruh tegangan tekan (Kegagalan Kolom) [7]

Ketika kekakuan lentur dari pelat dan kekakuan torsi dari penegar itu sama besar, maka model deformasi dari penegar dengan pelat ikutan ditunjukkan pada Gambar 2 [7].

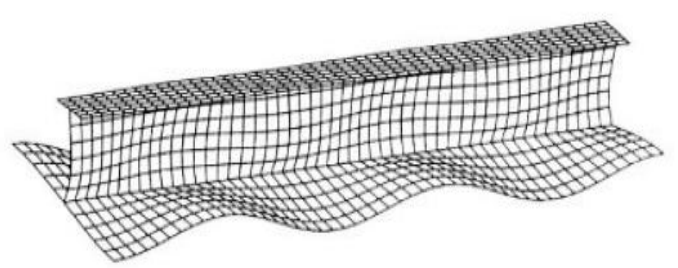

\section{Gambar 2. Bentuk deformasi dari sebuah penegar tertutup dengan pelat pengikut dalam pengaruh tegangan tekan [7]}

Kurva tegangan regangan dari material yang digunakan pada model elemen hingga harus tersedia. Kurva tegangan regangan sangat menentukan nilai kekuatan batas dari struktur kapal. Penelitian ini menggunakan spesifikasi material pada Tabel 1.

Tabel 1. Spesifikasi material [8]

\begin{tabular}{lcc}
\hline \multirow{2}{*}{ Spesifikasi Material } & \multicolumn{2}{c}{ Jenis Material } \\
\cline { 2 - 3 } & AH27 & AH36 \\
\hline Density $\left(\mathrm{kg} / \mathrm{m}^{3}\right)$ & 7850 & 7850 \\
ModulusYoung $\left(\mathrm{N} / \mathrm{mm}^{2}\right)$ & 210000 & 210000 \\
Poisson's Ratio & 0,3 & 0,3 \\
Yield Strength $\left(\mathrm{N} / \mathrm{mm}^{2}\right)$ & 290 & 370 \\
Tangent Modulus $\left(\mathrm{N} / \mathrm{mm}^{2}\right)$ & 625 & 675 \\
\hline
\end{tabular}

Material AH27 dan AH36 merupakan material khusus untuk marine. Modulus elastisitas sebesar $210000 \mathrm{~N} / \mathrm{mm}^{2}$, rasio poisson 0,3 dan tegangan luluh AH27 sebesar $290 \mathrm{~N} / \mathrm{mm}^{2}$, AH37 sebesar $370 \mathrm{~N} / \mathrm{mm}^{2}$ serta tangent modulus AH27 sebesar $625 \mathrm{~N} / \mathrm{mm}^{2}$ dan AH37 sebesar $675 \mathrm{~N} / \mathrm{mm}^{2}$. 
Kerangka konseptual yang digunakan pada penelitian ini berdasarkan pada analisa hubungan antara variabel-variabel terhadap tekuk yang disebabkan oleh perubahan jarak gading pada kapal ferry Ro-Ro. Kekuatan struktur kapal pada kondisi hogging dan sagging yang dihitung dengan menggunakan metode NLFEA dan metode Smith. Struktur kapal ferry terdiri dari struktur bottom, struktur geladak dan sisi. Struktur geladak terdiri dari pelat geladak, balok geladak dan penumpu geladak. Analisis tekuk dilakukan dengan memvariasiakan jarak balok pada pelat geladak. Rules atau klasifikasi menentukan struktur kapal, beban struktur, vertikal bending moment dan buckling. Beban struktur kapal terdiri dari beban bottom, beban geladak dan beban sisi. Pembebanan yang terjadi secara global dan lokal. Pembebanan global terjadi saat sagging dan hogging sedangkan pembebanan lokal terjadi akibat adanya beban lateral yang ditimbulkan oleh roda kendaraan. Momen lentur vertikal terjadi pada saat hogging dan sagging. Momen lentur batas vertikal dapat dihitung dengan menggunakan metode NLFEA dan Smith.

Berdasarkan formula di atas, maka nilai momen lentur batas vertikal pada bagian midship kapal ferry dapat diperoleh, baik pada saat kondisi sagging maupun kondsi hogging. Adapun hasil perhitungan momen lentur batas vertikal yang telah dihitung dapat dilihat pada perhitungan dan Tabel 1. berikut ini.

Tabel 2. Hasil perhitungan momen total saat kondisi hogging dan sagging

\begin{tabular}{ccc}
\hline Kondisi & $\begin{array}{c}\text { Sagging x10 } \\
\text { Nmm }\end{array}$ & $\begin{array}{c}\text { Hogging } \mathbf{x 1 0}^{\mathbf{1 1}} \\
\text { Nmm }\end{array}$ \\
\hline MSW & $-1,34844$ & 2.0372 \\
\hline MW & $-2,87524$ & 2.42438 \\
\hline Mt & -4.7987 & 4.9465 \\
\hline
\end{tabular}

Berdasarkan Tabel 2, momen lentur batas vertikal yang diakibatkan saat kondisi kapal ferry Ro-Ro mengalami sagging ketika air tenang adalah sebesar $-1,3484 \times 10^{11} \mathrm{Nmm}$ dan $-2,875 \mathrm{x}$ $10^{11} \mathrm{Nmm}$ saat air bergelombang dengan momen total sebesar $-4,7987$ x $10^{11} \mathrm{Nmm}$. Sedangkan momen lentur batas vertikal yang diakibatkan saat kondisi kapal mengalami hogging ketika air tenang adalah sebesar 2,0372 $\times 10^{11} \mathrm{Nmm}$ dan
$2,4244 \times 10^{11} \mathrm{Nmm}$ saat air bergelombang dengan momen total sebesar $4,9465 \times 10^{11} \mathrm{Nmm}$

Tabel 3. Kekuatan batas momen lentur kapal fery Ro-Ro

\begin{tabular}{cccc}
\hline Kondisi & $\begin{array}{c}\text { Metode Smith } \\
\text { Nmm }\end{array}$ & $\begin{array}{c}\text { NLFEA } \\
\text { Nmm }\end{array}$ & Rasio \\
\hline $\begin{array}{c}\text { Mu Hogging } \\
\text { x 10 } 12\end{array}$ & 1,491 & 1,797 & 1,202 \\
\hline $\begin{array}{c}\text { Mu Sagging } \\
\text { x 10 } 10^{12}\end{array}$ & $-1,418$ & $-1,4907$ & 1,051 \\
\hline
\end{tabular}

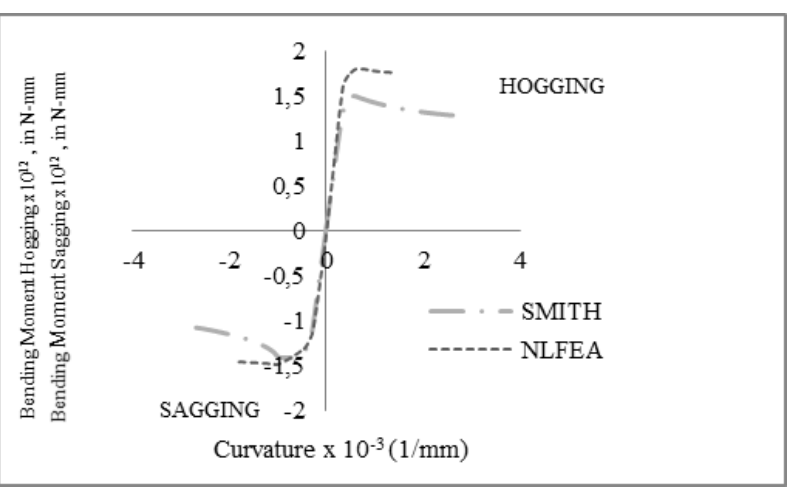

Gambar 3. Perbandingan momen kelengkungan metode Smith dan NLFEA ferry Ro-Ro

Berdasarkan Tabel 3, hasil analisis menggunakan metode NLFEA di Ansys lebih besar dari metode Smith, dimana persentase kedua metode tersebut sebesar $16,83 \%$ pada saat hogging dan $4,87 \%$ pada saat sagging. Hal ini disebabkan metode NLFEA dapat menghitung redistribusi beban dan interaksi antara kegagalan lokal dan global secara kompleks sehingga keakuratan hasil perhitungan metode NLFEA lebih baik daripada metode Smith [8].

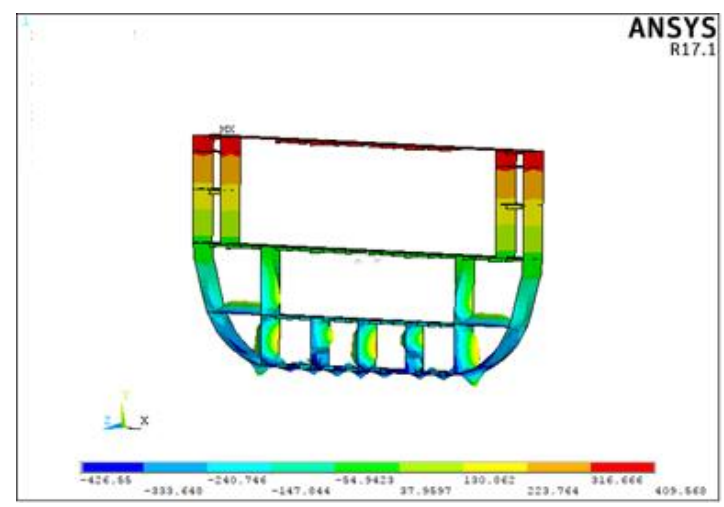

Gambar 4. Deformasi kekuatan-batas hull girder kondisi utuh akibat hogging 
Pada Gambar 4 nilai tegangan kerja yang terjadi pada struktur kapal ferry pada kekuatan batas pada strukturnya saat kondisi hogging adalah sebesar $-426,55 \mathrm{~N} / \mathrm{mm}^{2}$ di bottom dan tegangan terbesar terjadi pada deck kapal dengan nilai tegangan sebesar 409,568 N/mm². sedangkan pada saat sagging dapat dilihat pada Gambar 5.

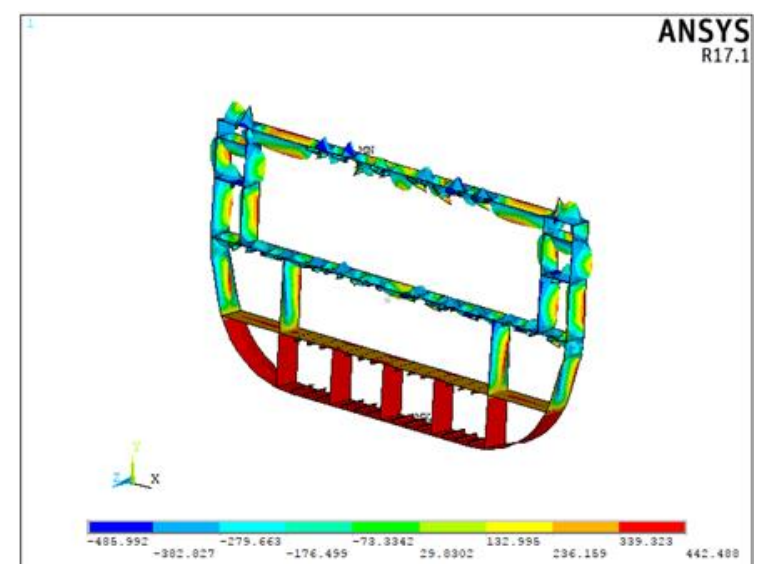

Gambar 5. Deformasi kekuatan-batas hull girder kondisi utuh akibat sagging

Berdasarkan Gambar 5 nilai tegangan kerja yang terjadi pada struktur kapal ferry Ro-Ro pada kekuatan batas pada strukturnya saat kondisi sagging adalah sebesar $-485,992 \mathrm{~N} / \mathrm{mm}^{2}$ di deck dan tegangan terjadi pada bottom kapal dengan nilai tegangan sebesar $442,488 \mathrm{~N} / \mathrm{mm}^{2}$.

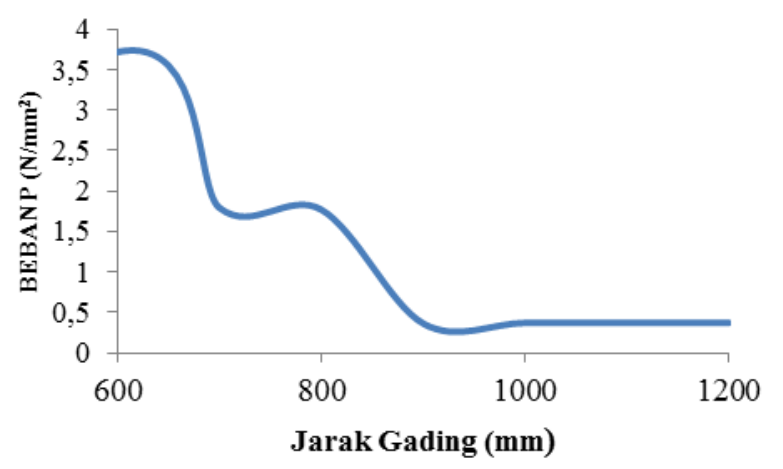

Gambar 6. Hubungan beban batas dan jarak gading

Beban yang digunakan adalah beban persatuan luas. Berdasarkan Gambar 6 maka diketahui nilai beban menurun secara signifikan seiring dengan bertambahnya jarak gading. Semakin jauh jarak gading maka beban yang diperlukan agar pelat mengalami tekuk menjadi sangat kecil.

\section{Kesimpulan}

Penelitian ini menggunakan metode Nonlinear Finite Element Analysis (NLFEA) untuk menginvestigasi momen lentur batas pada jarak gading terbesar yang akan dibandingkan dengan metode Smith dan beban batas pada masingmasing jarak gading serta peristiwa terjadinya tekuk pada masing-masing jarak gading dapat disimpulkan bahwa:

1. Hasil analisis menggunakan metode NLFEA di Ansys lebih besar dari metode Smith, dimana persentase kedua metode tersebut sebesar 16,83 \% pada saat hogging dan $4,87 \%$ pada saat sagging. Penggunaan aplikasi ANSYS yang menerapkan metode NLFEA pada penelitian ini menunjukkan perbandingan nilai hasil dari metode NLFEA lebih besar daripada metode Smith. Hal ini dikarenakan metode NLFEA dapat menghitung redistribusi beban dan interaksi antara kegagalan lokal dan global secara kompleks sehingga keakuratan hasil perhitungan metode NLFEA lebih baik daripada metode Smith.

2. Semakin jauh jarak gading maka beban yang diperlukan agar pelat mengalami tekuk menjadi sangat kecil.

\section{Referensi}

[1] Hughes O.F. \& Paik J.K. 2010. Ship Structural Analysis and Design. The Society of Naval Architects and Marine Engineers-SNAME, New Jersey.

[2] Susatio Yerri. Dasar-Dasar Metode Elemen Hingga. 2004. Andi Offset Yogyakarta.

[3] Lamb Thomas. Ship Design and Construction. 2003. The Society Of Naval Architects \& Marine Engineers.

[4] Hughes O.F. \& Paik J.K. 2010. Ship Structural Analysis and Design. The Society of Naval Architects and Marine Engineers-SNAME, New Jersey.

[5] IACS. 2016. Requirements Concerning of Strength of Ship.

[6] Biro Klasifikasi Indonesia (BKI). 2017. Volume II. Part 5. Seagoing Ships. Schodek L. D. 1998. Struktur. PT Rafika Aditama. Bandung.

[7] Shama, M. 2013. Buckling of Ship Structures. Springer, Verlag Berlin Heidelberg.

[8] Ship Structure Committee. 2015. Survivalibility of Hull Girder in Damaged Condition. Washington DC. 